\title{
DESCONTAMINAÇÃO DE CORPOS D'ÁGUA UTILIZANDO MESOCARPO DE COCO EM SISTEMA DE LEITO DIFERENCIAL, VISANDO A REMOÇÃO DE DERIVADOS DE PETRÓLEO
}

\author{
L. M. R. LIMA ${ }^{1}$, E. S. CARVALHO ${ }^{2}$, A. M. da SILVA ${ }^{3}$, F. O. $\operatorname{COSTA}^{3}$ e V. L. M. M. SILVA \\ ${ }^{1}$ Universidade Estadual da Paraíba - PB, Departamento de Engenharia Sanitária e Ambiental \\ ${ }^{2,4}$ Universidade Estadual da Paraíba - PB, Departamento de Química \\ ${ }^{3}$ Universidade Federal de Campina Grande - PB, Mestrado em Engenharia Química \\ E-mail para contato: ligiauepb@gmail.com
}

\begin{abstract}
RESUMO - O processo de adsorção em leito diferencial objetiva avaliar a viabilidade do uso do mesocarpo do coco como alternativa para descontaminação de corpos aquáticos. Foram realizados estudos da cinética e de equilíbrio, com experimentos variando-se a espessura do leito diferencial de biomassa $(2$ e $3 \mathrm{~mm})$ e as concentrações de contaminantes $(1 ; 3$ e 5\%). Foram usados efluentes simulados utilizando-se uma mistura de óleo diesel e gasolina em proporções iguais. Pode-se observar que a cinética de adsorção foi muito rápida e a quantidade adsorvida foi de aproximadamente $7 \mathrm{~mL} \cdot \mathrm{g}^{-1}$. Quanto aos experimentos em leito diferencial para a concentração de $1 \%$, tanto para a espessura de $2 \mathrm{~mm}$ quanto para a de $3 \mathrm{~mm}$, todo o contaminante foi adsorvido desde o primeiro minuto. Enquanto para a concentração de 3\%, embora tenha sido adsorvido completamente, o tempo para a adsorção completa do contaminante foi de 30 minutos. Para a concentração de $5 \%$ e espessura de $2 \mathrm{~mm}$ não houve completa adsorção em 120 minutos de experimento, havendo uma adsorção de $77,5 \%$ de contaminante. Com o aumento da espessura para $3 \mathrm{~mm}$ observou-se que para as concentrações estudadas, todo o contaminante foi adsorvido.
\end{abstract}

\section{INTRODUÇÃO}

A água é um recurso natural bastante utilizada pelo ser humano, seja para atividades individuais ou coletivas, a sua contaminação por substâncias derivadas do petróleo a desqualifica para o uso humano além de prejudicar todas as formas de vida das massas de águas (rios, lagos, mares). Mesmo em pequena quantidade, os contaminantes orgânicos são difíceis de serem removidos, pois são estáveis à luz, ao calor e biologicamente não degradáveis; diminuem a área de contato entre a superfície da água e o ar atmosférico impedindo, assim, a transferência de oxigênio da atmosfera para a água, além de apresentarem problemas estéticos, produzindo a rejeição do efluente (Dagallo e Smaniotto, 2005). Entre os principais efeitos danosos impostos ao meio ambiente, estão a formação de uma película superficial que dificulta as trocas gasosas entre o ar e a água; a vedação dos estômatos das plantas e órgãos respiratórios dos animais; a impermeabilização das raízes de plantas e a ação de substâncias tóxicas nele contidas para muitos organismos (Braga et al., 2003). Portanto há a necessidade de intervenções que reduzam ou até mesmo eliminem esses efeitos em corpos d'água que tenham sido contaminados. 
Existem diversos estudos relacionados à purificação de massas de água contaminadas. Dentre eles, o processo de adsorção encontra largo emprego por ser uma operação eficiente e de baixo custo quando da utilização de biomassas adsorventes.

A adsorção é um método bem conhecido para remover substâncias indesejadas de águas e solos contaminados. Há várias formas de se aplicar o processo de adsorção, dentre elas a adsorção em coluna e em leito diferencial, o qual consiste de uma fina camada de adsorvente em contato com o fluido que se deseja purificar. O processo em leito diferencial é preferencialmente aplicado para retirada de material líquido sobrenadante, enquanto a coluna é mais viável para fluxos d'água.

Biomassa é um termo utilizado para representar uma série de materiais orgânicos, como os resíduos agrícolas, que podem ser direta ou indiretamente empregados para a geração de combustíveis, como etanol, metanol, biogás, carvão vegetal e óleos (Santos et al., 2007).

O mesocarpo do coco foi escolhido como objeto de estudo, pois a produção anual de coco no Brasil é muito grande. Considera-se que, para que seja mantido um equilíbrio entre oferta e demanda, a produção ideal de coco seco no Brasil deveria ser da ordem de 500.000.000 de frutos, dos quais, 150 milhões (30\%) atenderiam as indústria de alimentos e 350 milhões (70\%) ao mercado in natura. Seria possível obter, assim, preços para os produtores e competitivos para a indústria. Este patamar somente seria alcançado quando as importações não ultrapassassem os $5.000 .000 \mathrm{~kg}$ de coco ralado ao ano, sob pena de reduzir o preço do coco nacional (Sindcoco, projeções com base em consultas informais feitas ao mercado). De acordo com o Levantamento Sistemático da Produção Agrícola do IBGE (www.ibge.gov.br), a produção de coco no ano de 2005 foi de 2,018 bilhões de frutos, considerando a colheita de coco seco e de coco verde (IBGE, 2006).

O objetivo do presente trabalho é avaliar a capacidade de adsorção do mesocarpo de coco seco e triturado frente a uma mistura heterogênea água/gasolina/óleo diesel, utilizando um sistema de leito diferencial. 


\section{MATERIAIS}

Os contaminantes orgânicos estudados, presentes no efluente contaminado simulado, foram gasolina básica tipo $\mathrm{C}$ e óleo diesel. Esses contaminantes estão presentes em diversos corpos d'água que muitas vezes servem para lavagem de carros e caminhões ou recebem águas de lavagem de postos de abastecimento de combustíveis.

A biomassa utilizada foi o mesocarpo de coco (Figura 1), que é a parte espessa e fibrosa, conforme mostra a Figura 2. O qual foi retirado de resíduos de coco, obtidos no município de Campina Grande, no Estado da Paraíba. Esses resíduos encontravam-se depositados a céu aberto quando de sua coleta.

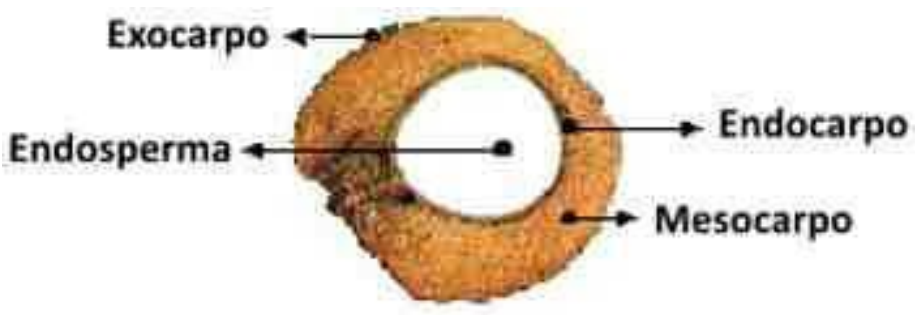

Figura 1 - Partes internas do coco.
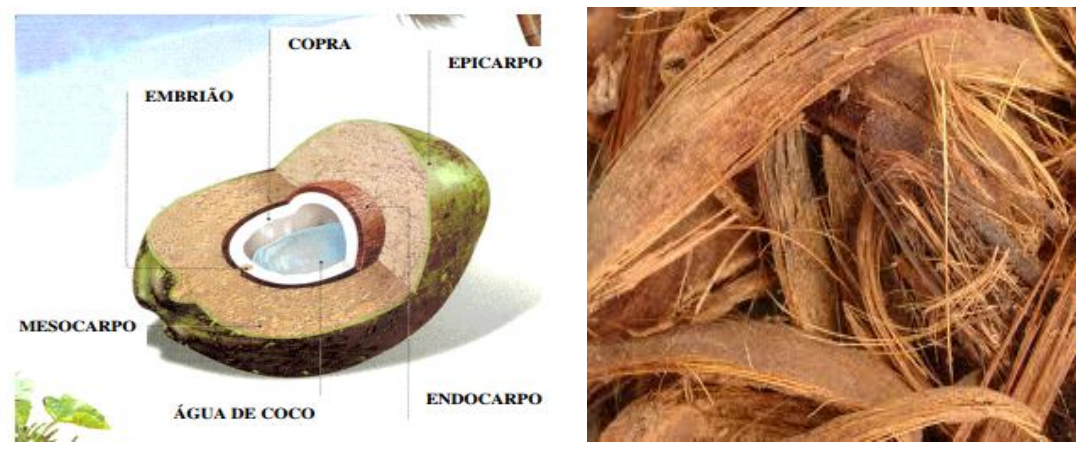

Figura 2 - Imagem do mesocarpo do coco.

Fonte: Disponível em http://coqueiro-anao.blogspot.com.br/2013/05/tipos-de-cultura-do-coqueiroanao.html.

\section{METODOLOGIA}

Inicialmente houve a preparação da biomassa, o mesocarpo do coco foi separado do exocarpo (parte mais externa da casca) e triturado em máquina forrageira, em seguida triturado em um liquidificador industrial e peneirado em peneiras de série Tyler com granulometria referente a 10 mesh apresentando $1,70 \mathrm{~mm} / \mu \mathrm{m}$ de porosidade, de forma a se obter a biomassa na 
granulometria desejada. Após preparada a biomassa acondicionou-se em recipientes devidamente etiquetados para posterior uso.

\subsection{Obtenção da Isoterma de Equilíbrio}

Para obtenção da isoterma de adsorção foi usado um sistema rotatório, conforme mostra a Figura 3, ao qual eram acopladas tubetes contendo $0,2 \mathrm{~g}$ de biomassa e 6,0 $\mathrm{mL}$ da dispersão água/gasolina/óleo diesel, variando a concentração inicial de 5 a $50 \%$. Os tubetes eram totalmente vedados para que não houvesse perda do material. $\mathrm{O}$ sistema rotatório ficava acoplado ao eixo horizontal de um agitador mecânico, o qual tinha sua rotação ajustada para $600 \mathrm{rpm}$, ficando o material sob agitação durante 60 minutos e, em temperatura ambiente para em seguida, ser medido o volume final da dispersão, tendo assim por diferença, a quantidade de óleo adsorvida pela biomassa.

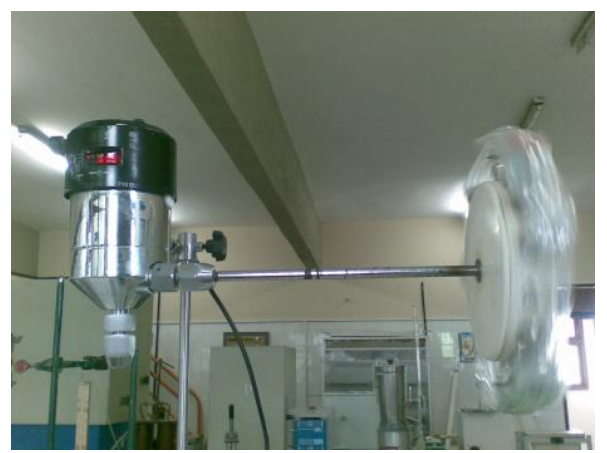

Figura 3 - Equipamento usado para as avaliações de equilíbrio

O modelo utilizado para ajustar a isoterma de adsorção, foi o de Langmuir, cuja equação é definida por:

$$
\frac{q}{q_{g}}=\frac{b c}{1+b c}
$$

Em que, q/q $\mathrm{q}_{\mathrm{s}}=$ taxa de adsorção; $\mathrm{q}_{\mathrm{s}}$ é a máxima capacidade de adsorção; b é o parâmetro da equação de Langmuir e c é a concentração do adsorbato na fase líquida.

\subsection{Avaliações em Leito Diferencial}

A biomassa foi pesada de acordo com a espessura da camada a ser utilizada e em seguida uniformizada em uma tela. A quantidade de biomassa necessária para cada espessura foi pesada em uma balança analítica, sendo realizados experimentos em duas espessuras: 2 e $3 \mathrm{~mm}$. Para a espessura de $2 \mathrm{~mm}$ de biomassa pesou-se 10,8123 g de biomassa e para a espessura de $3 \mathrm{~mm}$ de biomassa pesou-se $16,2185 \mathrm{~g}$ da mesma. Foi utilizado um paquímetro digital para a medição da espessura do leito. 
Logo após, a tela era colocada dentro do reservatório que continha a amostra de água com o contaminante. O tempo de contato entre água contaminada e a biomassa variou, entre $1 \mathrm{e}$ 120 minutos de acordo com a concentração inicial de contaminante. Após o tempo estabelecido, media-se o volume final do contaminante em uma proveta e por análise volumétrica, era obtida a quantidade adsorvida. Sendo o contaminante uma mistura de proporções iguais de gasolina e óleo diesel.

O sistema empregado para a adsorção em leito diferencial de biomassa era composto de um reservatório de vidro com uma capacidade máxima de trabalho igual a 4 litros, para conter a mistura de óleo diesel/gasolina/água e uma tela de alumínio na qual o mesocarpo do coco era depositado de maneira uniforme, conforme mostra a Figura 4.
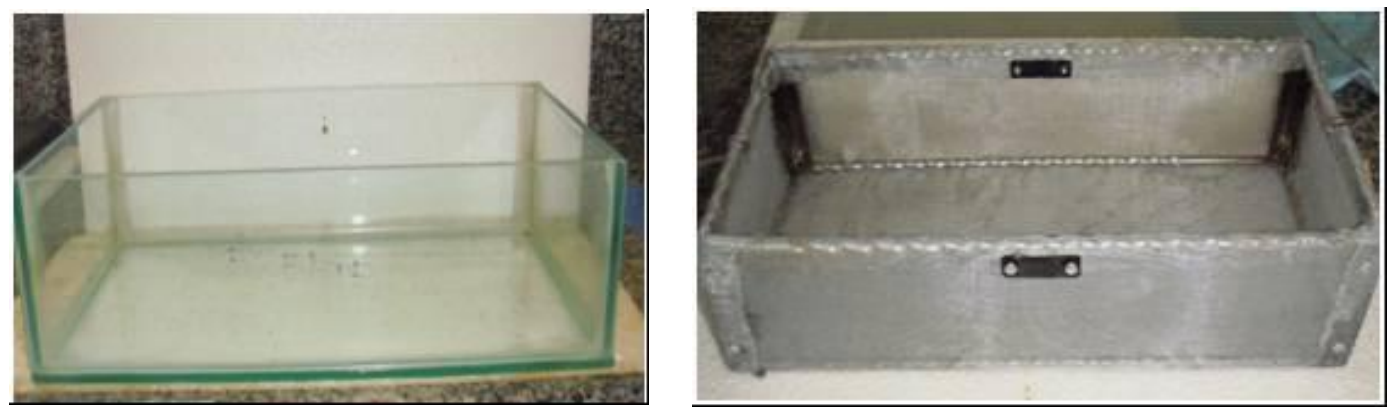

Figura 4 - Sistema para adsorção em leito diferencial.

Os experimentos foram realizados com concentrações de 1,3 e 5\%, de contaminantes, sendo essa porcentagem correspondente a mistura de gasolina e óleo diesel em partes iguais, dispersos em água, de modo que o volume total da dispersão foi sempre 4 litros.

O mesocarpo do coco depositado na tela de alumínio, de acordo com a espessura selecionada, foi colocado em contato com a mistura heterogênea de gasolina/óleo diesel/água, contida no reservatório. No final destes tempos estabelecidos, a tela de alumínio contendo o mesocarpo do coco era retirada do reservatório de vidro para haver a separação da mistura heterogênea da biomassa. Em seguida foi analisada a quantidade adsorvida do contaminante em relação ao mesocarpo do coco, por meio de análise volumétrica. Na Figura 5 pode ser visto a biomassa em contato com a mistura heterogênea água/gasolina/óleo diesel.

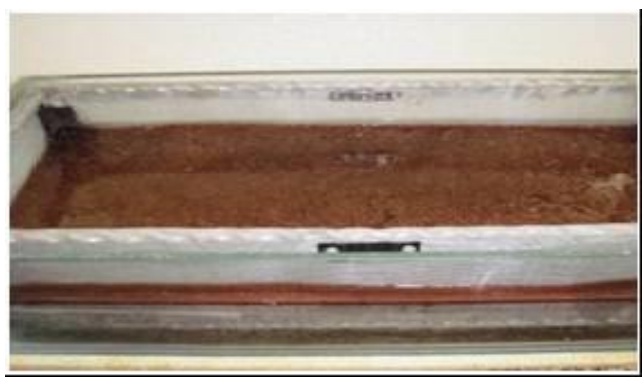

Figura 5 - Tela de alumínio contendo leito de biomassa em contato com água contaminada. 


\section{RESULTADOS E DISCUSSÃO}

\subsection{Isoterma de Adsorção}

A isoterma de adsorção da mistura água/gasolina/óleo diesel em mesocarpo de coco, obtida segundo metodologia descrita anteriormente, conforme mostra a Figura 6.

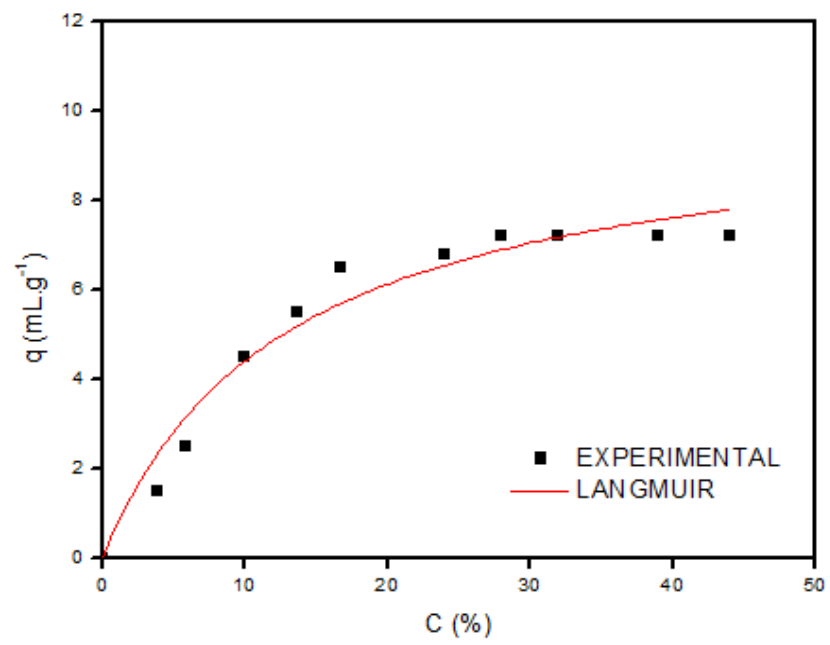

Figura 6 - Isoterma de adsorção da mistura heterogênea água/gasolina/óleo diesel.

Pode-se observar, conforme mostra a Figura 6, que os dados experimentais foram bem ajustados pelo modelo de Langmuir. A quantidade máxima adsorvida no equilíbrio foi de aproximadamente $7 \mathrm{~mL}$ da mistura água/óleo diesel/gasolina, indicando que a biomassa obtida a partir do mesocarpo de coco, pode ser usada como adsorvente para o sistema estudado.

\subsection{Leito Diferencial}

Os resultados obtidos usando o sistema de leito diferencial de mesocarpo de coco para adsorção da mistura água/gasolina/óleo diesel com espessura do leito iguais a 2 e $3 \mathrm{~mm}$, estão mostrados nas Figuras 7 e 8, respectivamente.

A partir dos resultados pode-se observar que para ambas as espessuras, há um ótimo desempenho da biomassa para todas as concentrações estudadas. Observa-se também que, quanto maior a concentração do contaminante, maior a quantidade adsorvida indicando que há um maior contato entre o contaminante e a biomassa, diminuindo o efeito de adsorção conjunta da água, pois as biomassas adsorventes tendem a adsorver a água, além do contaminante (Morais, 2005). 


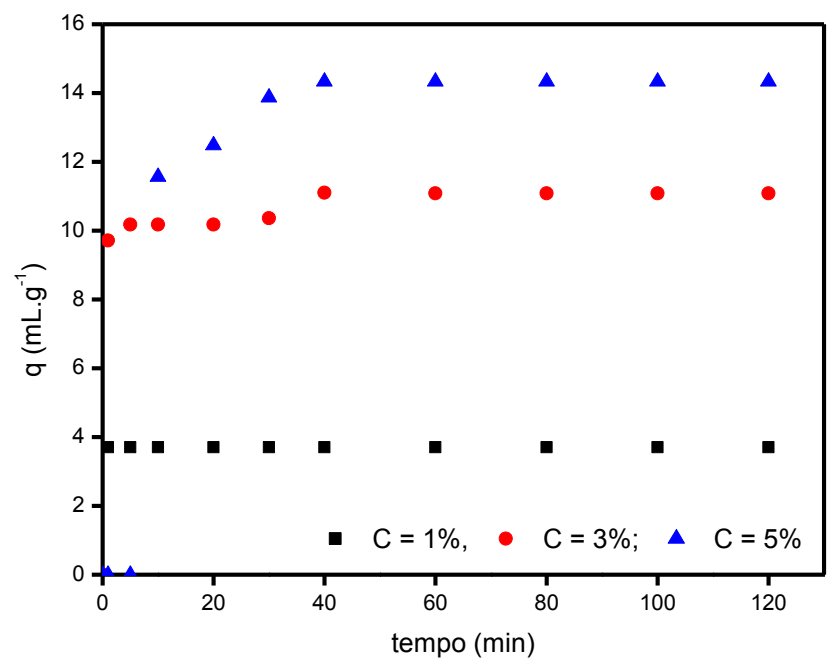

Figura 7 - Cinética de adsorção da mistura água/gasolina/óleo diesel em leito diferencial de mesocarpo de coco com espessura de $2 \mathrm{~mm}$ para concentrações de contaminante iguais a 1, 3 e $5 \%$.

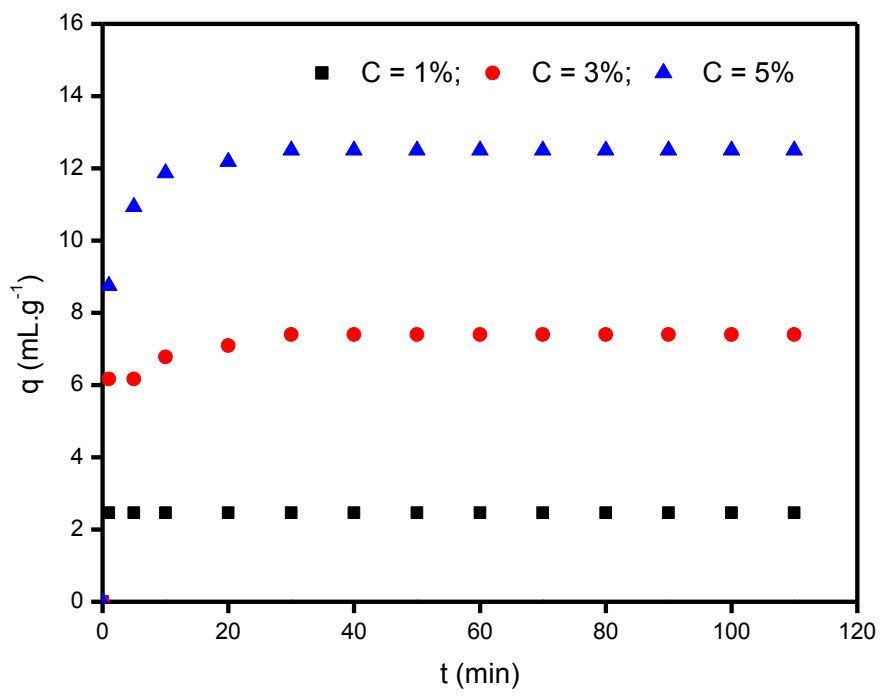

Figura 8 - Cinética de adsorção da mistura água/gasolina/óleo diesel em leito diferencial de mesocarpo de coco com espessura de $2 \mathrm{~mm}$ para concentrações de contaminante iguais a 1, 3 e $5 \%$.

\section{CONCLUSÕES}

De acordo com os estudos realizados, foi possível concluir que:

- A isoterma de adsorção foi bem ajustada pelo modelo de Langmuir, indicando ser favorável à adsorção. 
- As avalições em leito diferencial mostraram que para todas as concentrações e espessuras estudadas, houve um ótimo desempenho da biomassa para o sistema estudado.

- Quanto maior a concentração, maior a quantidade adsorvida para ambas as espessuras estudadas, indicando maior contato do contaminante com o adsorvente, reduzindo o efeito de adsorção conjunta de água.

- Por todos os resultados obtidos, verifica-se que o mesocarpo de coco pode ser uma promissora biomassa para adsorção de contaminantes derivados do petróleo, como gasolina e óleo diesel.

\section{REFERÊNCIAS}

BRAGA, B.; HESPANHOL, I.; LOTUFO, J. G. Introdução à Engenharia Ambiental - O Desafio do Desenvolvimento Sustentável. Editora Prentice Hall. $2^{\mathrm{a}}$ Ed, 2005.

COQUEIRO-ANÃO, disponível em http://coqueiro-anao.blogspot.com.br/2013/05/tipos-de-culturado-coqueiro-anao.html. Acesso, 22 de março de 2014.

DALlAGO, R. M.; SMANIOTTO, A. Quim. Nova, v. 28, p. 433, 2005.

MORAIS, V. L. M. Purificação de Efluentes Contaminados com Hidrocarbonetos por Adsorção em Leito Fixo de Biomassa. Doutorado em Engenharia de Processos - UFCG, Campina Grande - PB, p. 104, 2005.

SANTOS, E. G. ALSINA, O. L. S., SILVA, F. L. H. Desempenho de Biomassas na Adsorção de Hidrocarbonetos Leves em Efluentes Aquosos. Quím. Nova, v. 30, n. 2, p. 327 - 331, 2007. 